\title{
RAÇA, GÊNERO E COLONIALIDADE: INTERPELAÇÕES EPISTEMOLÓGICAS NA PRODUÇÃO CRIMINOLÓGICA CRÍTICA BRASILEIRA
}

\author{
Humberto Ribeiro Junior ${ }^{1}$ \\ Rayane Marinho Rosa ${ }^{2}$
}

\begin{abstract}
Resumo
O presente trabalho se constitui como uma revisão bibliográfica que objetiva refletir a necessária articulação dos estudos feministas, raciais e decoloniais para a constante (re)construção de uma epistemologia criminológica que busca a compreensão da realidade social brasileira. O pensamento criminológico dominante, bem como a maioria dos outros campos do saber, se demonstra como uma ciência orientada por noções masculinas, de branquidade e eurocêntricas. Dessa forma, buscamos suscitar: i) a assimilação dos discursos positivistas e racistas na criminologia brasileira; ii) as contribuições e impactos das teorias feministas, raciais e decoloniais nas estruturações metodológicas e epistemológicas nesse campo; e iii) aludir as necessárias imbricações das categorias raça, gênero, classe e localização geopolítica interconectadas com a modernidade e a colonialidade. As reflexões expostas neste trabalho permitiram constatar como tais teorias auxiliam a reexaminar premissas e conceitos, bem como a partir da empiria revisitar as teorias até então produzidas, ampliando as percepções da questão criminal.
\end{abstract}

Palavras-chaves: epistemologias, criminologia crítica, criminologias feministas, racismo, decolonialidade.

\section{Considerações Iniciais}

Investigações científicas advém de inquietações que lhes antecedem. O presente trabalho nasce de uma delas: a verificação do quanto o saber criminológico ainda é tão engendrado em concepções androcêntricas, racistas e colonialistas.

\footnotetext{
${ }^{1}$ Doutor em Sociologia e Direito (PPGSD/UFF). Mestre em Filosofia e Teoria do Direito (PPGD/UFSC). Professor do Mestrado em Segurança Pública da Universidade Vila Velha (PPGSPo/UVV). Coordenador do Grupo de Pesquisa Zacimba Gaba - Criminologias, Segurança Pública e Políticas Prisionais (UVV/ES). Universidade Vila Velha - UVV, Espírito Santo - Brasil. ORCID iD: http://orcid.org/0000-0002-1542-1161 Lattes: http://lattes.cnpq.br/3619044317727659 E-mail: E-mail: humbertorj@gmail.com

${ }^{2}$ Mestranda em Ciências Sociais (PGCS/UFES) - Bolsista CAPES/FAPES (Edital 003/2017). Graduada em Direito (UFES). Integrante do Núcleo de Estudos em Transculturação, Identidade e Reconhecimento (NETIR/UFES) e do Grupo de Pesquisa Zacimba Gaba - Criminologias, Segurança Pública e Políticas Prisionais (UVV/ES). Universidade Federal do Espírito Santo - UFES, Espírito Santo - Brasil. ORCID iD: http://orcid.org/0000-0003-0441-9741 Lattes: http://lattes.cnpq.br/9906464703004433 $\quad$ E-mail: rayanemarinhorosa@gmail.com.
} 
À contrassenso, o pensamento criminológico, bem como a maioria dos outros campos do saber, ainda se demonstra como uma ciência dominada e visibilizada por noções masculinas, de branquidade e euro-eua-cêntricas. Ou seja, contraditoriamente, uma teoria que se diz à margem, na perspectiva crítica, pode acabar por reproduzir tais concepções institucionalmente.

Ora, se a Criminologia Crítica $^{3}$ busca a compreensão da questão criminal tratando todo o sistema social, político e econômico, o processo de criminalização e de seletividade, e os mecanismos da realidade social, como ela tem se desenvolvido cientificamente baseada numa ótica hegemônica masculinizada e racista que não se atenta devidamente à realidade concreta do Brasil? Como tratar de forma complexa um contexto latino-americano se utilizando majoritariamente de teorias eurocêntricas - por conseguinte localizadas e limitadas?

Repensar epistemologias não se trata somente, como tentam demonstrar as epistemologias feministas e negras, de "incluir" novos sujeitos como objetos de análise. Os estudos de gênero na década de 1980 já questionavam os pressupostos científicos capazes de interferir na própria epistemologia das ciências em geral - frise-se, aqui, a criminologia. Ou seja, para entender o sistema em sua forma mais complexa e ampla, a criminologia crítica precisa, de forma constante, indagar as suas próprias formulações teóricas e metodológicas, até então construídas sob a égide da ciência moderna, na medida em que isso invisibiliza saberes e resistências, que passam a ser tidos como subalternos.

Ainda permanece como desafio para essa problemática metodológica a ampliação das compreensões que deem conta da realidade latino-americana, abarcando a lente contra-hegemônica.

Por isso, soma-se a um caminho já percorrido por criminólogas e criminológos que ousaram pensar a partir da realidade concreta sociopolítica do continente ${ }^{4}$, os pensamentos pós-coloniais e decoloniais ${ }^{5}$ que podem contribuir nessa metodologia que pretende refletir seu momento histórico, seu próprio contexto. A ideia central destes estudos é demonstrar como a empreitada dominadora

\footnotetext{
${ }^{3}$ Entende-se por Criminologia Crítica, um movimento do pensamento criminológico contemporâneo que visa uma percepção materialista do desvio, dos comportamentos socialmente negativos e da criminalização, movimento este transdisciplinar e não homogêneo (BARATTA, 2011, p.159). Diferencia-se da "tradicional" quando se desloca para compreender o processo de criminalização a partir de uma interpretação macrossociológica, percebendo as relações de poder que irão determinar esse processo (BARATTA, 2011, p. 211; ANDRADE, 2007, p. 54). Como sintetiza Thula Pires (2017, p. 546), tal concepção foi alicerçada a partir de reflexões advindas da teoria do etiquetamento, antipsiquiatria, marxismo e ceticismo, além do pensamento crítico e radical dos pensadores da América Latina.

${ }^{4}$ Pensar uma Criminologia para a América Latina não é uma novidade, como já nos apontava Rosa del Olmo (2004), Lola de Castro (2005) e Zaffaroni $(1991,1992)$. Tais contribuições serão adequadamente suscitadas no segundo item deste trabalho.

${ }^{5}$ Adota-se na presente proposta a terminologia decolonial ao invés de descolonial no mesmo sentido que descreveu Cattharine Walsh. Apesar de não ser unânime, trata-se de uma demarcação política, que a diferenciaria do projeto de descolonização. Nesse sentido, "la intención, más bien, es señalar y provocar un posicionamiento -una postura y actitud continua- de transgredir, intervenir, in-surgir e incidir. Lo decolonial denota, entonces, un camino de lucha continuo en el cual podemos identificar, visibilizar y alentar "lugares" de exterioridad y construcciones alternativas" (WALSH, 2009, pp. 14-15, nota de rodapé).
} 
do colonialismo - que em outras épocas serviu ao projeto de colonização econômica, política e administrativa do Terceiro Mundo - assume hoje novas formas, perdurando em nossas intersubjetividades e intelectualidade.

Os estudos decoloniais feministas dão continuidade às críticas já denunciadas pelos feminismos negros, que compreendem o quanto as teorias tradicionais não dariam conta na interpretação das opressões sofridas pelas mulheres racializadas e de origens de territórios colonizados (ESPINOSA-MIÑOSO, 2014, p. 8).

Aliás, daí decorre também outro alinhamento teórico: as perspectivas negras criminológicas. Isso porque a criminologia, reconhecida como crítica nas suas premissas, acaba por reproduzir o "monopólio conservador da branquitude nas suas posturas analíticas", segundo descreve brilhantemente Ana Flauzina na contracapa da obra de Luciano Góes (2016).

À vista disso, objetivou-se no presente trabalho explorar de que forma as categorias de gênero, raça, classe e localização geopolítica se refletem como categorias essenciais a serem imbricadas em quaisquer teorias críticas das humanidades, em específico, da criminologia brasileira. Para isso, as indagações centrais que norteiam esse artigo são: é possível um diálogo entre a Criminologia Crítica, a Criminologia Feminista, os Feminismos Negros ${ }^{6}$ e os estudos decoloniais? De que maneira ressaltar gênero, raça e localização geopolítica pode contribuir na compreensão da realidade social brasileira e seus mecanismos de controle e de seletividade?

Para isso, o presente trabalho abordou inicialmente a assimilação dos discursos criminológicos positivistas e racistas na América Latina, bem como a importância da reformulação epistemológica e metodológica do campo, a partir das contribuições sobremaneira de Luciano Góes (2016) e Evandro Piza Duarte (2011). Em seguida, pretendeu-se percorrer as contribuições dos estudos feministas na criminologia, levantadas em especial por Carmen Hein de Campos (2014), Soraia da Rosa Mendes (2014) e Zaffaroni (1992), identificando-se ainda inconsistências que perduram nesse campo crítico. Ainda neste segundo tópico, percorremos os estudos criminológicos latinoamericanos, com as obras das venezuelanas Lolita Aniyar de Castro (2005) e Rosa Del Olmo (2004) para, após, aludir acerca dos estudos pós-coloniais e decoloniais, mormente as contribuições de Espinosa-Miñoso (2014), que alerta para a necessária imbricação de raça, classe, gênero e sexualidade, interconectadas com a modernidade e a colonialidade. Por fim, a partir desse emaranhado de aportes teóricos, pretendeu-se no último tópico evidenciar como os aportes teóricos

\footnotetext{
${ }^{6}$ Importante ressaltar que existem "feminismos negros" em suas mais variadas interpretações e análises. Inclusive, ver trabalho de Figueroa e Hurtado (2014) sobre vertentes como o feminismo afrolatino-americano e o feminismo africano. Como aduz Collins, o "pensamento feminista negro" seria como um mosaico de ideias e interesses concorrentes, obviamente com contradições, fricções e inconsistências, mas concordando com a autora, neste trabalho enfatizaremos nas peças do mosaico e em suas contribuições como um todo coerente por uma opção política (COLLINS, 2000, p. xiii, do Prefácio).
} 
dialogados interpelam para uma revisitação de premissas, categorias, métodos e epistemes do campo criminológico acima tratadas ajudam a revisitar conceitos e teorias, bem como a reexaminar a empiria, ampliando as percepções da questão criminal evidentes no cárcere feminino e no sistema de justiça criminal.

Dessa forma, a hipótese é de que as formulações teóricas levantadas possam ensejar necessárias contribuições à criminologia crítica, de modo a compreender as especificidades do desenvolvimento do controle punitivo nas chamadas sociedades periféricas, como é o caso do Brasil.

\section{A assimilação dos discursos criminológicos positivistas e racistas na América Latina e no Brasil}

Os discursos dos campos de saberes possuem processos constitutivos e são empregados de acordo com cada contexto. No curso do desenvolvimento da criminologia, assim como diversas outras áreas de conhecimento, os discursos científicos engendrados demonstram-se construídos historicamente com base no paradigma moderno. A pressuposição de um conhecimento científicosob a alcunha do "universal" e "neutro", de aura pura, e legitimado para ser natural, válido e objetivo, na realidade, silenciou e excluiu sujeitos, experiências, conhecimentos ${ }^{7}$.

Dessa forma, o paradigma de ciência moderna se constituiu como universal, determinando o que é ciência/civilização e o que não é; deslegitimando saberes que não estão no centro de referência do Norte Global. Tal prisma, ao legitimar o eurocentrismo e sua racionalidade como hegemonia, se constituiu como um sistema de dominação epistêmica, que representa uma lógica colonizadora e que é limitada, obviamente, ao seu contexto.

Como outras autoras afirmaram, esta ágora moderna possui um sujeito nativo do seu âmbito, o único capaz de habitá-lo com naturalidade porque é dele oriundo. E este sujeito, que formulou a regra da cidadania à sua imagem e semelhança, porque a originou a partir de uma exterioridade plasmada no primeiro processo bélico e imediatamente ideológico que instalou a episteme colonial e moderna, tem as seguintes características: é homem, é branco, é pater familiae - portanto, é funcionalmente heterossexual -, é proprietário, e é letrado (SEGATO, 2012, p. $\mathrm{s} / \mathrm{n})$.

Ainda, segundo Segato (2012),“o binarismo do Um - universal, canônico, 'neutral' - e seu outro - resto, sobra, anomalia, margem" reflete o binarismoeurocêntrico e colonial quena estrutura da colonialidade foi construindo a forma de alteridade ainda estruturante até os dias atuais: $U m$

\footnotetext{
${ }^{7}$ Sobre as críticas feministas ao fazer ciência moderno ocidental, ver Fox Keller (2006); Löwy (2000); Haraway (1995); Schiebinger (2001) e hooks (1995).
} 
como o padrão e as outras formas de alteridade como um problema. Aliás, "esse engessamento de posições identitárias é também uma das características da racialização, instalada pelo processo colonial moderno, que impele os sujeitos para posições fixas dentro do cânone binário aqui constituído pelos termos branco - não branco" (SEGATO, 2012, p. s/n).

Esse processo de desumanização dos não-brancos, produto da colonialidade, foi a todo tempoconformado e legitimado por um conjunto de práticas e discursos. Na formação do controle penal moderno, a produção científica foi mobilizada para corroborar com velhas práticas e teorias, justificando a manutenção do status quo. Nesse contexto de pós-abolição ${ }^{8}$, a necessidade de manutenção da ordem hierárquica-racial brasileira fez com que o processo de tradução da teoria lombrosiana em rodrigueana legitimasse a prática de ordem e de controle racial segregacionista (GÓES, 2017, p. 279).

Inicialmente já ressaltamos que partimos do pressuposto, na esteira do que adverte Evandro Piza Duarte (2011, p. 206), de que as contribuições de juristas e criminológos brasileiros, como Tobias Barreto, Nina Rodrigues e Clóvis Beviláqua, sobre a produção criminológica futura, não foram simplificadamente 'causas' das práticas racistas da sociedade brasileira, mas, ao contrário, manifestam-se como respostas das relações de poder e como forma de se perpetuarem tais práticas discriminatórias.

As ideias cientificistas, evolucionistas, positivistas e racistas do século XIX encontraram no Brasil um território fértil para se recriaremem um paradigma racista/etiológico, como um processo de metamorfose, através da "tradução" do paradigma racial de Lombroso pelo médico Nina Rodrigues:“era a ideia da 'boa miscigenação', gestada pela ciência marginal, que interpretou a teoria original de modo singular, marco de uma ciência à brasileira" (GÓES, 2017, p. 63).

Ou seja, não foi só um processo de recepção/assimilação simples. Nina Rodrigues, num diálogo centro-margem, potencializa os passos de Lombroso, inserindo a mestiçagem como fator degenerativo na teoria original (daí sua originalidade), além de substituir o estereótipo pelo fenótipo como reconhecimento da inferioridade - logo, da criminalidade (GÓES, 2016, p. 280). Importa frisar que, apesar de uma aparente derrota na formalização de um apartheid brasileiro, que por pouco não foi implementado, suas contribuições teóricas e práticas reformuladas puderam dar seguimento à política assimilacionista "que fundou a farsa de nosso paraíso racial”(GÓES, 2017, p. 62; GÓES, 2016, p. 283).

Expostas em linhas gerais, é relevante enfrentarmos justamente as permanências do positivismo e desse racismo científico e, seja no campo criminológico tradicional, seja nos resquícios e reflexos ainda presentes na criminologia crítica. Se o negro foi alçado a objeto de

\footnotetext{
${ }^{8}$ Para um aprofundamento a respeito do percurso histórico do controle sociopunitivo no período colonial e póscolonial, conferir Prando(2006).
} 
investigação científica desde o pós-colonial, urge rompermos isso radicalmente nas nossas produções.

Ao analisar as rupturas e permanências na trajetória do pensamento brasileiro acerca da seletividade penal, Felipe Freitas (2016, p. 490) enfatiza o "silêncio criminológico" perante o tema das relações raciais, buscando também hipóteses explicativas. Apesar do pioneirismo nas formulações teóricas a respeito do falacioso discurso penal, do encarceramento e do extermínio, bem como do perfil racial e passado escravista brasileiro, para ele, tais constatações não foram suficientes para a aproximação do campo com o movimento negro e sua demanda em relação ao racismo estrutural da sociedade brasileira (FREITAS, 2016, p. 491). Ao produzir sobre as categoriasde raça e de gênero apenas como aspectos periféricos, não se comprometendo com a dimensão estrutural do racismo, os pesquisadores hegemônicos do campo acabam por demonstrar suas escolhas relacionadas às suas posições de poder e hierarquia (FREITAS, 2016, pp.493-494).

É o que denunciam Calazans, Duarte, Prando e Cappi (2016, pp. 454-455), quando apontam que a criminologia crítica tem dado respostas à questão criminal que dizem muito mais sobre o poder da branquidade ${ }^{9}$ na Academia, seus privilégios e posturas de silenciamentos, do que realmente uma abordagem que se aprofundasse no racismo e nas relações raciais em si. Para Thula Pires (2017, p. 548) esse silenciamento é fruto do "pacto narcísico" quanto a sua branquitude, um acordo tácito (consciente ou não) de não reconhecimento de como seus privilégios - materiais e simbólicos - coadjuvam para a (re)produção do racismo.

Apesar das produções acerca dos caminhos de resistência da negritude brasileira e do racismo estrutural, como Duarte (2002), Flauzina (2017), Goés (2016) e Freitas (2016), a Criminologia enquanto campo científico - dominado pela branquidade - não tem conseguido incorporar com centralidade o racismo, não se inteirando das "relações que podem se estabelecer entre o racismo, o sexismo e o sistema penal” (FRANKLIN, 2017, pp. 489-490).

Fato é que os criminólogos críticos, diferentemente dos positivistas e clássicos, apontaram a seletividade racial do controle social, a racialização do sistema penal, e evidenciaram seus reflexos na "perversa estratégia de estigmatização" (PIRES, 2017, p. 547). Por isso, são aliados históricos dos movimentos negros, motivo pelo qual todas essas críticas são expostas, não como

\footnotetext{
${ }^{9}$ Os autores Duarte, Queiroz e Costa $(2016$, p. 1) exploram que há uma variação quanto ao emprego de "branquidade" e "branquitude", sintetizando o primeiro como "a identidade racial branca não questionadora de seus privilégios", adotado como tradução do termo whiteness, empregado na obra de Vron Ware "Branquidade: identidade branca e multiculturalismo" (2004), enquanto o termo "branquitude" indicaria "o indivíduo branco que questiona suas vantagens raciais".
} 
rompimento $^{10}$, mas como um verdadeiro convite para produzirmos alternativas pujantes e potencializar a criminologia contemporânea (PIRES, 2017, pp. 544-547).

Ainda que denunciando o racismo institucional, essa tradição criminológica, reproduzindo a narrativa do "negro-tema", "abordou a clivagem racial do sistema penal, a partir de categorias e valores eurocêntricos e de uma visão do negro esteriotipada e homogeneizada" (PIRES, 2017, p. 547). Ou seja, se desenvolveu de maneira a interpretar apenas a classe trabalhadora branca, masculina, hetero, negando a dimensão estrutural e estruturante da raça e de gênero, de modo ser necessário alcançar outros padrões imbricados a classe "sob pena de não ser possível descolonizar a criminologia" (PIRES, 2017, p. 551).

\section{As contribuições dos estudos feministas e latino-americanos para a criminologia}

Paradoxalmente, como já exposto,o pensamento criminológico, ainda que sob o manto da crítica, se mostra como uma ciência dominada e visibilizada por noções masculinas, de branquidade e eurocêntricas.

Necessitando, então, tratar como a questão de gênero foi identificada na construção do saber criminológico até a atualidade, nos remetemos à obra de Soraia da Rosa Mendes (2014), na qual, não por acaso, aponta no primeiro capítulo que sua busca findou em um sentimento deinconformidadeante ao fato de que os conhecimentos criminológicos “pouco ou nada dizem sobre as mulheres como sujeitos de realidades históricas, sociais, econômicas e culturais marcadas por diferenças decorrentes de sua condição" (2014, p. 73). Era um "discurso de homens, para homens e sobre homens" (MENDES, 2014, p. 157).

Não à toa, que os estudos de gênero passaram a apontar a necessidade de se utilizar uma lente de gênero(LÖWY, 2000) - e acrescento aqui uma lente "racial" e "decolonial" - para desconstruir tais percepções, entendendo o conhecimento como de fato ele é: localizado e contextualizado. À vista disso, para o paradigma feminista não bastaríamos "incluir" as questões raciais e das mulheres no conhecimento até aqui produzido. Ou seja, frise-se o quanto, por vezes, as categorias de gênero e de raça são tidas apenas como variáveis, apensos, como se pudessem ser "somadas" as análises já existentes ou construídas como "disciplinas marginais" que não interfeririam em todo o campo. Esquecem, por consequência, a necessidade de uma releitura

\footnotetext{
${ }^{10}$ Em outras palavras: "longe de uma caçada, pretende-se promover um espaço de escuta, de revisão dos próprios trabalhos através do reconhecimento dos códigos através dos quais a branquitude opera e de aprimorar a crítica através do enfrentamento ao racismo, em outros termos" (PIRES, 2017, p. 594).
} 
constante de categorias, conceitos e pressupostos para a permanente construção epistemológica de uma criminologia verdadeiramente libertária.

Queremos dizer, dessa forma, que as abordagens feministas despertam não somente a necessária visibilização das mulheres, em suas múltiplas experiências, como também a imprescindível ressignificação em termos teóricos, metodológicos e epistêmicos.

Reconhecendo as contribuições feministas à crítica da ciência androcêntrica, Baratta (1999, p. 20) admite o quanto tal paradigma assegura a dominação masculina, ao mesmo tempo em que esconde e mantém ignorada a questão de gênero. Zaffaroni (1992, p. s/n, tradução nossa) alerta que essa omissão é suspeita, ao passo que uma omissão em um discurso, em regra, "esconde uma das facetas de sua perversão"11.

Analisar o controle punitivo e a seletividade somente com base no exercício de poder das agências de criminalização foi insuficiente, já que não revelava toda a extensão e menos ainda toda a intensidade do controle punitivo (ZAFFARONI, 1992, p. s/n). Negligenciava, não por acaso ou por coincidência, "a maior parte - e a mais importante - do poder punitivo, que é o poder de vigilância” (ZAFFARONI, 1992, p. s/n, tradução nossa) ${ }^{12}$. Sendo, em essência, o poder verticalizante do modelo corporativo da sociedade, esse poder de vigilância nada mais é do que a contrapartida da criminalização. Importa, por último, evidenciarmos que o poder de vigilância não é menos importante, nem incide menos, pois é tão fundamental e estruturantequanto, sendo necessário não hieraquizarmos para compreender de fato todo o controle social.

As leituras acerca da constituição do controle punitivo moderno na América Latina e, mais especificamente, no Brasil, precisam levar em conta as peculariedades de nossa região marginal. Se as análises da formação e dos discursos legitimadores do controle punitivo na Europa Ocidental mais especificamente França e Inglaterra - relacionam-se com a formação do Estado Moderno (logo, tendo como objeto os meios institucionais e publicizados de punição), questiona-se como a constituição do controle sociopunitivo na realidade marginal colonizada é marcada por especificidades (PRANDO, 2006, pp. 77-85).

No Brasil Império já no século XIX, apesar do discurso liberal adotado, contraditoriamente nosso modelo produtivo ainda era alicerçado na escravidão. Deste modo, enquanto a legislação, como o Código Penal de 1830, se alinhava aos ideários contratualistas e disciplinaristas da Europa, as condições histórico-econômicas não permitiram, aqui, a funcionalização da pena privativa de liberdade nos mesmos moldes que nos países centrais.

\footnotetext{
11 “oculta una de las facetas de su perversión” (ZAFFARONI, 1992, p. s/n).

12 "la mayor parte - y la más importante - del poder punitivo, que es el poder de vigilancia" (ZAFFARONI, 1992 , p. $\mathrm{s} / \mathrm{n}$ )
} 
A prisão por aqui não se alinhou totalmente à ideia do panóptico e da disciplina das massas marginalizadas em um mercado de trabalho capitalista. Também o controle privado senhorial não foi substituído, mas complementado a partir de novas complexidades de organização punitiva, como a resistência quilombola, que demandaram certa especialização do controle social, caracterizado por alto grau de violência e controle subterrâneo (PRANDO, 2006, pp. 86-89). Dessa forma, toda a construção jurídico-penal na nossa margem foi nesse sentido de conter o medo branco diante das rebeliões dos negros escravizados, tendo a escravidão como sua matriz conceitual.

Ao se constatar um distanciamento entre o desenvolvimento do controle penal latino-americano e seus discursos legitimadores importados da Europa Central, a Criminologia latino-americana torna-se atenta para as diversidades da emergência do controle punitivo, e depara-se com a compreensão histórica da existência de sistemas penais paralelos e subterrâneos (PRANDO, 2006, p. 87).

Nesse sentido, inconformada pela inexistente ou escassa referência à América Latina nas histórias do pensamento criminológico - escrita por especialistas dos países hegemônicos - Rosa del Olmo ${ }^{13}$ se propõe em sua obra percorrer e narrar esse desenvolvimento, tanto para contribuir na incorporação do continente, quanto para superar diversos "mitos cientifícos" propagados, que tanto sustentam a dependência necolonial (DEL OLMO, 2004, pp. 17-19).

É esse um desafio que a aproximação decolonial nos faz destacar: há uma história da criminologia latino-americana que precisa ser levada a sério nas nossas análises. Lola Aniyar de Castro (2005), criminóloga pioneira que, mesmo no cenário marcado por ditaduras no continente, se destacou entre os juristas latino-americanos insatisfeitos com a incapacidade do positivismo hegemônico em dar conta das problemáticas do controle social na periferia do capitalismo, ressaltava a importância de conhecer os esforços, por vezes até sangrentos ${ }^{14}$, do desenvolvimento e reafirmação de uma criminologia própria.

Assim, desde 1974, a partir dos Grupos Latino-americano de Criminologia Comparada e de Criminologia Crítica, foram dirigidos esforços para examinar as realidades específicas de cada país, e de entender como se trata de um processo de (re)construção constante (DE CASTRO, 2005, pp. 22-34). Diferente do positivismo que se consagrava como único critério de cientificidade, a teoria criminológica latino-americana (ou melhor, uma forma de fazer criminologia na América Latina) deverá ser sempre em revisão, uma atividade crítica permanente,dando conta das diferenças locais,

\footnotetext{
${ }^{13}$ Rosa del Olmo é uma grande intelectual e militante crítica engajada para incorporar a América Latina à história da criminologia.Nos dizeres de Vera Malaguti Batista (2004), é uma das maiores intelectuais do continente: "não hesito em afirmar que ela seria muito mais reconhecida se pertencesse ao 'gênero' masculino".

${ }^{14}$ A autora ao narrar, no primeiro capítulo de sua obra Criminologia da libertação, o processo de constituição dos grupos e do movimento para a construção de uma teoria crítica do controle social na América Latina, denuncia o perigo de se fazer criminologia crítica, libertadora, por ser perigosa aos que exercem o poder, citando colegas professores que sofreram 'acidentes' ou foram assassinados no contexto de ditaduras militares em seus países (DE CASTRO, 2005, pp. 28-29).
} 
articulando a situação de dependência e colonização, até porque "os criminólogos críticos de amanhã tampouco serão os criminólogos críticos de hoje" (DE CASTRO, 2005, p. 61 e 105).

A criminologia que se viveu na América não escapou à problemática da dependência, inclusive da ciência: "na Europa e nos Estados Unidos gestou-se a criminologia tradicional [...]. Como o positivismo pretendia fazer ciência universal, pouco importava a realidade sociopolítica em que seus resultados se aplicaram" (DE CASTRO, 2005, pp. 20-21). Não que as teorias centrais devam ser ignoradas, mas há de se considerar as diversas formas de controle social nas estruturas marginais e dependentes de poder, como o Brasil, onde também perdurou por mais tempo a escravidão. Daí a relevância em perceber que essas criminólogas e criminólogos já propunham a necessidade de uma criminologia “feita na América Latina e para a América Latina” (DE CASTRO, 2005), e como aprodução de conhecimento advinda da América Latina, pela ampliação de seu objeto, contribui significativamente para o campo criminológico crítico.

Por conseguinte, soma-se a esse caminho,já percorrido por criminólogos que ousaram pensar a partir da realidade concreta sociopolítica do continente, os pensamentos pós-coloniais e decoloniais que podem contribuir nessa metodologia que pretende refletir seu momento histórico, seu próprio contexto, como discutiremos no próximo tópico.

\section{Epistemologias insurgentes: os estudos pós-coloniais e decoloniais}

Entendendo a importância de considerarmos as complexidades dos sujeitos, seus contextos históricos e as relações de poder existentes, o presente trabalho evoca ainda os estudos pós-coloniais e decoloniais como importantes contribuições a serem consideradas no campo criminológico.

Apesar das críticas do hibridismo da terminologia pós-colonial, que poderia remeter tanto a um período histórico de pós-colonização, quanto a uma possível superação dos países colonizados da exploração do imperialismo, nos interessa aqui, para além de demarcar as ambiguidades, ressaltar a importânciada crítica pós-colonial.

É, sobretudo, a partir dos precursores Albert Memmi (1977), Aimé Césaire (2010), Franz Fanon (2010), somado a Edward Said (2007), tido como pioneiro desse modelo de pensamento, que a teoria pós-colonial começa a tomar forma assumindo as experiências coloniais como estruturantes da supremacia da ordem capitalista e das novas relações de poder (MIGLIEVICH-RIBEIRO, 2014, p. 67).

Essa rede crítica intelectual é fortalecida pelos estudos culturais britânicos, pela revisão historiográfica realizada pelos estudos subalternos da África e da Ásia, assim como somada às 
reflexões de autores latino-americanos, e ainda com o pós-colonial português Boaventura de Souza Santos (2010), compreendendo essa rede teórica pós-colonial em suas distintas perspectivas e peculiaridades (MIGLIEVICH-RIBEIRO, 2014, p. 67).

Segundo Luciana Ballestrin, o pós-colonial consiste no "conjunto de contribuições teóricas oriundas principalmente dos estudos literários e culturais, que a partir dos anos 1980 ganharam evidência em algumas universidades dos Estados Unidos e da Inglaterra” (BALLESTRIN, 2013, p. 90). Ainda que não de maneira unívoca, em um sentido amplo e geral, a autora compreende o movimento como sendo comprometido com a superação das relações de colonização, colonialismo e colonialidade (BALLESTRIN, 2013, p. 91).

Nessa seara, importante diferenciar o processo de colonização e colonialismodaquilo que os autores demarcam comocolonialidade. Colonialismo compreende a empreitada imperialista dos países europeus que colonizaram as Américas entre os séculos XVI e XIX e a Ásia e a África, entre os XVIII e XX. Ou seja, se refere à dominação territorial que implicou na subordinação dos colonizados tanto a nível econômico e político, como também cultural.

Ao passo que os teóricos pós-coloniais explicitam como esse fenômeno não implicou somente no momento histórico do imperialismo, mas ainda reverbera e estrutura as nossas relações no presente em uma "face oculta da modernidade: a colonialidade" (MIGLIEVICH-RIBEIRO, 2014, p. 68). Nos dizeres de Restrepo e Rojas (2010, p. 15), a colonialidade é um fenômeno histórico mais complexo, que se inicia com a colonização, no entanto se estende até o presente, e compreende um padrão de poder que opera através da naturalização de hierarquias territoriais, raciais, culturais e epistêmicas, possibilitando a reprodução de relações de dominação. Assim, “o colonialismo continua construindo subjetividades, corporalidades, conhecimentos, espacialidades e práticas sociais" (ANDRADE, 2017, p. 73).

Isso porque mesmo após o período de colonização não ocorreu uma ruptura tanto em suas dimensões políticas e econômicas, quanto a nível epistêmico. Por isso, destaca-se a dimensão cognitiva e simbólica do colonialismo, que criou um imaginário sobre o mundo social do subalterno (o oriental, o negro, o índio, o campesino) para legitimar o poder imperial a partir dessa sujeição colonial de colonizadores e colonizados (CASTRO-GÓMEZ, 2005, p. 20).

Para explicitar esse processo, as teóricas e teóricos pós-coloniais e decoloniais sublinham importantes estruturas que merecem aqui nosso destaque: a racialização do mundo para a supremacia do capitalismo como eixo estrutural da modernidade, já explicitada no primeiro tópico do artigo, a constituição de alteridade ("o outro") ocidental e a colonialidade de gênero, a seguir trabalhadas.

A radicalização das reflexões pós-coloniais no continente latino-americano impulsionoua teorização dos estudos decoloniais. Inicialmente, a realidade da América Latina foi sendo 
introduzida no debate pós-colonial a partir do Grupo Latino-Americano dos Estudos Subalternos. No entanto, parte de seus membros acreditava que não rompendo totalmente com autores eurocêntricos, o grupo continuaria ocultando a própria trajetória latinoamericana, momento em que, por divergências teóricas, o coletivo se desagregou, formando em seguida o Grupo Modernidade/Colonialidade (BALLESTRIN, 2013, pp. 94-96). Dessa forma, o giro decolonial "significa o movimento de resistência teórico e prático, político e epistemológico, à lógica da modernidade/colonialidade" (BALLESTRIN, 2013, p. 105).

Como toda construção de conhecimento, a crítica decolonial é reelaborada e alicerçada a partir de conhecimentos híbridos e heterogêneos, advindos desde a linhagem crítica e anticolonialista do pensamento latino-americano, à teologia e filosofia da libertação, até a teoria da dependência, se aproximando ainda nos anos 80 com os debates da modernidade e da pósmodernidade, e nos anos 90, com os estudos culturais; sendo influenciada ainda pelos estudos subalternos sul-asiáticos, pós-coloniais, pela filosofia africana e pelos estudos feministas (MIGLIEVICH-RIBEIRO, 2014, p. 73).

Fazemos notar, previamente, que as teóricas e os teóricos decoloniais, em suas diversidades e distinções, não possuem obviamente uma leitura unívoca, nem mesmo tem-se aqui pretensão de se partir de um local essencializado de América Latina.

Até por isso, compreende-se a magnitude e a importância da teoria decolonial, já que coubelhes apontar que as teorias produzidas em outras realidades geopolíticas não poderiam simplesmente serem assumidas e transferidas sem nenhuma análise adicional à nossa realidade. Dessa forma, compreender as limitações (e a não-universalidade) de teorias e produções que tem seus lócus de enunciação coloniais é, para esses autores, se aproximar da tradição do pensamento crítico latino-americano que já fazia frente aos resquícios coloniais ibéricos, bem como as outras formas de colonialismo e imperialismo como asbritânicas e as norte-americanas. Ou seja, é produzir com lócus na América Latina.

É também a partir dessa premissa que AdéliaMiglievich-Ribeiro (2014, p. 68) explica a importância de se ressaltar a colonialidade para que haja, por um lado, uma "contextualização das categorias explicativas (e normativas) até então naturalizadas como absolutas" e suas ressignificações, e por outro lado, uma crítica pós-colonial que identifica na cosmovisão moderna hegemônica a exclusão e desumanização a partir da diferença colonial.

Para a dominação do projeto colonial, “o dominador europeu construiu o 'outro' como objeto de conhecimento (oriente) e também construiu uma imagem egocêntrica de seu próprio locus enuntiationis (ocidente) no processo de exercer domínio" (CASTRO-GÓMEZ, 2005, p. 21). Essa subjugação e homogeneização dos sujeitos colonizados no imaginário social ainda se reverberam nas nossas subjetividades, afetividades e sociabilidades. 
É justamente criticando essa construção da alteridade (do 'outro') da civilização europeia a partir da mentalidade obsidional ocidental, que ainda está tão embrenhada até na nossa forma de pensar e é tão fundamental para a manutenção do poder, que Vera Malaguti Batista e Nilo Batista(2017) alertam para a necessidade de se produzir um pensamento descolonizante e descolonial sobre a questão criminal. Produzir direito penal, criminologia e política criminal a partir dos nossos lugares, mergulhando na nossa história, compreendendo a história do controle social no Brasil mediante as matrizes ibéricas, o genocídio colonizador e a gênese da escravidão para então produzir uma criminologia descolonial ${ }^{15}$ (BATISTA, 2017).

\subsection{As contribuições feministas decoloniais}

Os autores decoloniais irão frisar como a categoria raça foi essencial para a empreitada colonizadora, na medida em que construída na justificação desse 'outro' como diferente, inferior, em relação ao ideal moderno europeu. Para Quijano (2000, p. 368), trabalho, raça e gênerosão as três linhas articuladas que classificam as pessoas uma estrutura global por meio da colonialidade de poder. Referenciado nas contribuições das perspectivas feministas e de diferenças raciais subalternas, Grosfoguel (2007, p. 213) nos lembra que a fala é sempre a partir de determinado local nas estruturas de poder, onde ninguém escaparia da diferença de classe, sexualidade, gênero, espiritualidade,hierarquias lingüísticas, geográficas e raciais do "sistema-mundo moderno/colonial/capitalista/patriarcal".

É justamente essa necessária imbricação entre raça-sexo-gênero como produto da modernidade que as feministas decoloniais irão fazer questão de frisar. María Lugones (2014), filósofa argentina, problematiza a noção de “colonialidade do poder” de Quijano, complexificando e introduzindo o conceito de "colonialidade de gênero".

Não mais como apenso, a colonialidade de gênero é entendida como categoria fundamental, como o que constitui o sistema de poder capitalista global, pois além de classificar os povos, realiza um processo de redução ativa das pessoas, tornando algumas menos que serem humanos: as/os colonizadas/os. E ressalta-se: “diferentemente da colonização, a colonialidade de gênero ainda está conosco" (LUGONES, 2014, p. 939). Ou seja, a adoção/internalização construída socialmente para um processo de subjetificação ainda é presente (LUGONES, 2014, pp. 939-942).

Lugones (2014) ainda dá ênfase à relação oprimir versus resistir, demonstrando interesse na resistência, de modo que sublinha as resistências concretas e vividas à colonialidade de gênero.

\footnotetext{
${ }^{15}$ Apesar de ter registrado a opção conceitual pela categoria "decolonial" neste trabalho, uso o termo "descolonial" neste parágrafo em conformidade com os autores referenciados.
} 
Isso porque o processo de colonização não é totalmente vitorioso, há uma tensão entre o que é construído pelo colonizador/colonialidade e a subjetividade ativa das/os colonizadas/os contra a invasão colonial: "seres tanto oprimidos como resistentes", "continuamente resistido e resistindo até hoje" (LUGONES, 2014, p. 942). Daí a importância em decolonizar o gênero, sendo essa possibilidade de superação denominada de "feminismo descolonial” (LUGONES, 2014, p. 941).

Também é nesse seguimento que chamamos ao debate as contribuições de Yuderkys Espinosa-Miñoso (2014) para uma produção teórica antirracista e decolonial. Dando continuidade ao legado do feminismo negro, de cor e das afrodescendentes, a autora sustenta que o feminismo decolonial demonstra como a teoria feminista clássica produzida por um grupo específico de mulheres, que têm o privilégio epistêmico graças às suas origens de classe e raça, não servia para interpretar a realidade de mulheres racializadas e de origens de territórios colonizados (ESPINOSAMIÑOSO, 2014, pp. 7-8).

Mesmo as epistemologias feministas que conseguiram incorporar a demanda das mulheres negras, não conseguiram romper com "as premissas básicas da teoria feminista hegemônica de uma opressão baseada no gênero, como categoria dominante fundamental para explicar a subordinação das mulheres" (ESPINOSA-MIÑOSO, 2014, p. 9). Ou seja, como se o uso da categoria de gênero presumisse uma experiência comum de forma universalista, e os demais demarcadores raça/classe não modificassem a própria concepção feminista.

Esse ocultar a imbricação das categorias raça/classe/gênero/sexualidade como estruturas de dominação, e relutar abandonar os velhos quadros interpretativos hegemônicos, Espinosa nomeia "racismo de gênero":

Uma impossibilidade da teoria feminista de reconhecer o seu lugar de enunciação privilegiada dentro da matriz moderna colonial de gênero, impossibilidade que emerge de sua negação a questionar e abandonar este lugar ao custo de "sacrificar", invisibilizando diligentemente, o ponto de vista das "mulheres" em menor escala de privilégio, ou seja, as racializadas empobrecidas dentro de uma ordem heterossexual(ESPINOSA-MIÑOSO, 2016, p. 50, tradução nossa) ${ }^{16}$.

Por isso, o feminismo decolonial para Espinosa-Miñoso (2014) é uma aposta epistêmica, na medida em permite uma epistemologia que legitime saberes situados partindo de uma experiência concreta.

Perceba que ao tratar dessa articulação das categorias como forma analítica para a criminologia não se quer, nem abandonar a centralidade da noção de raça na classificação e

\footnotetext{
16“"Una imposibilidad de la teoría feminista dereconocer su lugar de enunciación privilegiada dentro de la matrizmoderno colonial de género, imposibilidad que se desprende de sunegación a cuestionar y abandonar este lugar a costa de 'sacrificar', invisibilizando diligentemente, el punto de vista de 'las mujeres'em menor escala de privilegio, es decir las racializadas empobrecidas dentro de un orden heterossexual".
} 
dominação social, nem mesmo pretender explicar todas as categorias em uma única (ANDRADE, 2017, p. 91; GOMES, 2018, p. 79). A questão é que "nem a raça sozinha promoveu essa forma de inferiorização dos sujeitos, nem o gênero sozinho produz hierarquizações, estereótipos ou relações de dominação" (GOMES, 2018, pp. 78-79).

$\mathrm{Na}$ linha do que estamos sustentando, evidentemente, pensar gênero deve nos remeter muito mais a uma concepção moderna e ocidental do que universalizante ${ }^{17}$. Por isso, chamamos ao debate as contribuições de Camilla de Magalhães Gomes (2018, p. 78) que ressalta o perigo de teorias, conceitos e práticas que, mesmo querendo se afastar do "homem universal", se deslocam para a "mulher universal" ao essencializar sujeitos e experiências.

Fazendo analogia à Angela Davis (2016), tanto classe informa a raça, quanto raça informa classe, assim como gênero informa raça e vice-versa e, ainda, gênero informa a colonialidade, de maneira que não é possível pensar colonialidade sem incluir gênero. Nessa senda, "a raça e o racismo, junto à ideia de que alguns sujeitos possuíriam sexo e outros gênero, como quem se opõe natureza e cultura, que criaram a ideia de não-humanos racializados"(GOMES, 2018, p. 79, grifos no original). O que se sugere, portanto, é que tais mecanismos não se sustentaram separadamente e de forma impermeável, devendo a Criminologia Crítica necessariamente se atentar a essas articulações como categorias explicativas e analíticas.

\section{Interpelações ao fazer científico criminológico: o sistema de justiça criminal sob novos olhares}

Retomando o questionamento inicial de refletir a compreensão da realidade sócio-punitiva brasileira considerando as questões de gênero, raça e localização geopolítica, percebemos como essas epistemologias acima tratadas ajudam a revisitar conceitos e teorias, bem como a reexaminar a empiria, ampliando as percepções da questão criminal.

À título de exemplo, os dados mais recentes produzidos especificamente sobre as mulheres privadas de liberdade no Brasil por si sós constituiriam uma demanda analítica. Sabe-se que a população carcerária feminina no período de 2000 a 2016 aumentou de cerca de 6 mil à marca de 42 mil custodiadas, representando um crescimento de 656\% (INFOPEN MULHERES, 2017, p. 14). Ressaltando-se que destas, $45 \%$ nem sequer foram condenadas, e no que tange ao perfil, $62 \%$ são mulheres negras $^{18}$ (INFOPEN MULHERES, 2017, p. 19 e 40).

\footnotetext{
${ }^{17}$ Como já nos demonstrou Segato (2018) e Marilyn Strathern (2006).

${ }^{18}$ Ressalta-se que a categoria negra, segundo o IBGE, inclui pretas e pardas. Além disso, a informação sobre raça/etnia só estava disponível para $72 \%$ dessa população, não representando o todo populacional.
} 
No entanto, se os números de encarceramento assustam e demonstram o alvo a ser criminalizado no Brasil, diante do acúmulo teórico proposto, não poderíamos nos restringir somente ao que é visível, ou reflexo das agências de controle formal. A realidade é que a matriz central da punição se sustenta fundamentalmente nas mulheres negras (FLAUZINA, 2016, p. 97)

Ainda que sejam os homens mais criminalizados - em sua maioria negros - é na exploração das mulheres negras o sistema penal se ampara. A função feminina viabiliza o encarceramento masculino, seja provendo sustentos, nas filas dos presídios, no acompanhamento judicial, são elas quem pagam a fatura do abandono (FLAUZINA, 2016, p. 97-100). Em síntese, "é no lombo das pretas que o encarceramento vai mantendo sua estrutura vilipendiosa e exterminadora no Brasil" (FLAUZINA, 2016, p. 102). Uma contribuição invisibilizada, não obstante ser fundamental na dinâmica do controle social. A dinâmica decorre em grande medida da exploração financeira, emocional e sexual de mulheres, "onerando desproporcionalmente as mulheres negras nesse secular processo de genocídio do povo preto no Brasil" (FLAUZINA, 2016, p. 102; PIRES, 2017, p. 558).

Ao observar os acúmulos expostos, é significativo para problematizar o andamento do encarceramento como projeto materializado de uma política genocida, "assumido desde a Abolição da escravatura, com a qual nunca se rompeu efetivamente" (FLAUZINA, 2017, p. 147). Nesse sentido, esse projeto político de genocídio se demonstra como uma chave de explicação para compreender como o racismo se opera (PIRES, 2017, p. 557).

As formulações teóricas levantadas nos ensejam acerca da realidade de um sistema de justiça criminal sedimentado no racismo, no machismo, no classismo e no colonialismo, enquanto estruturantes do sistema punitivo brasileiro.

É preciso reconhecer que o racismo estrutura as narrativas sobre nossa noção de humanidade. Não é só a bala da arma que mata, mas uma série de dispositivos físicos e simbólicos que vão impedindo a possibilidade de afirmação da humanidade negra em nossa sociedade (FREITAS, 2016, p. 495).

Portanto, ao lado da denúncia do caráter seletivo e de extermínio do sistema penal, precisamos também discutir nossas escolhas metodológicas e teóricas através de uma lente epistemológica imbricada (PIRES, 2017) que rompa radicalmente com as estruturas opressoras que condicionaram nossas formulações a fim de uma construção da nossa criminologia verdadeiramente crítica. Isso significa não apenas uma localização crítica de nossas teorias, entendendo as especificidades de nossos lócus de enunciação, como também análises que tenham responsabilidade com a centralidade das categorias de raça, gênero e colonialidade, capazes de reformular toda a teoria da questão criminal, conceitos, métodos e epistemes do fazer criminológico. 


\title{
Considerações Finais
}

As reflexões expostas neste trabalho permitiram constatar como a produção hegemônica acadêmica do campo criminológico ainda é marcada por noções masculinas, de branquidade e eurocentradas. Tomamos como fio condutor os aportes teóricos da Criminologia Crítica, em suas vertentes feministas e negras para escancarar inconsistências que ainda perduram nesse campo crítico. Soma-se a isso o caminho traçado por importantes teóricas e teóricos que buscaram e ainda buscam a construção de uma criminologia à margem, comprometidos com a nossa realidade latinoamericana, aliando ainda os pensamentos pós-coloniais e decoloniais, a fim de desvelar a necessidade de contextualização e ressignificações teóricas e metodológicas. Além da denúncia quanto à racialização do sistema penal, as contribuições das feministas negras decoloniais se mostraram essenciais para frisar a necessária imbricação de categorias para nossas análises criminológicas.

Ao fim e ao cabo, os desafios postos ao campo criminológico a partir das críticas e contribuições dos saberes feministas, negros e decoloniais alertam para a urgente necessidade de revisão das epistemologias modernas. São essas necessárias reformulações de categorias e concepções centrais norteadoras que buscamos evidenciar no domínio teórico, a fim de umaconstrução de uma criminologia brasileira, cada vez mais referenciada a partir das nossas histórias, nossos sujeitos e especificidades para um campo verdadeiramente libertário.

\section{RACE, GENDER AND COLONIALITY: EPISTEMOLOGICAL NTERPELLATIONS IN CRITICAL BRAZILIAN CRIMINOLOGICAL PRODUCTION}

\begin{abstract}
The present work constitutes a bibliographical review that aims to reflect the necessary articulation of the feminist, racial and decolonial studies for the constant (re) construction of a criminological epistemology that seeks the understanding of the Brazilian social reality. The dominant criminological thinking, as well as most other fields of knowledge, shows itself to be a science oriented by masculine, whiteness and Eurocentric notions. In this way, we seek to discuss: i) the assimilation of positivist and racist discourses in Brazilian criminology; ii) the contributions and impacts of feminist, racial and decolonial theories on methodological and epistemological organizations in this field; and (iii) alluding to the necessary overlapping of race, gender, class, and geopolitical location, connected with modernity and coloniality. The reflections exposed in this work allow such theories to help reexamine premises and concepts, as well as from the empirical revisit as produced theories, expanding the perceptions of the criminal issue.
\end{abstract}

Keywords: epistemologies, critical criminology, feminist criminologies, racism, decoloniality 


\section{Referências}

ANDRADE, Camila Damasceno de. O controle penal moderno: colonialidade do poder e aprisionamento feminino. Revista Brasileira de Ciências Criminais, São Paulo, Ed. RT, v. 129, ano 25, p. 69-105, mar. 2017.

ANDRADE, Vera Regina Pereira de. A soberania patriarcal: o sistema de justiça criminal no tratamento da violência sexual contra a mulher. Direito Público, Porto Alegre, ano 5, n. 17, p. 5275, jul./set. 2007. Disponível em: <http://dspace.idp.edu.br:8080/xmlui/handle/123456789/5601>.

BARATTA, Alessandro. Criminologia crítica e crítica ao direito penal: introdução à sociologia do direito penal. 6. ed. Rio de Janeiro: Revan, 2011.

. "O paradigma do gênero: da questão criminal à questão humana". In: CAMPOS, Carmen Hein de (org). Criminologia e Feminismo. Porto Alegre: Sulina, 1999.

BATISTA, Vera Malaguti. "Prefácio". In: DEL OLMO, Rosa. A América Latina e sua criminologia. Rio de Janeiro: ICC/Revan, 2004. p. 11-16.

.; BATISTA, Nilo. Criminologia crítica e crítica ao direito penal brasileiro. Defensoria SP. Disponível em: <https://www.youtube.com/watch?v=FZ4zJ7omK6s >. Acesso em: 11 jan. 2019.

BRASIL. Levantamento Nacional de Informações Penitenciárias - INFOPEN Mulheres - $2^{\circ}$ ed. Brasília: Ministério da Justiça e Segurança Pública, Departamento Penitenciário Nacional, 2017. Disponível em: $\quad<$ http://depen.gov.br/DEPEN/depen/sisdepen/infopenmulheres/infopenmulheres_arte_07-03-18.pdf $>$.

CAMPOS, Carmen Hein de. Criminologias Feministas: Três possibilidades para a constituição de um campo de estudo. In: ANDRADE, V.R. P.; ÀVILA, G.N.; CARVALHO, G.M.. (Org.). Criminologias e Política Criminal. Florianópolis: CONPEDI, 2014. v. 01, p. 187-201.

CALAZANS, Marcia Esteves de. et al. Criminologia crítica e questão racial. Caderno do CEAS, Salvador, n. 238, p. 450-463, 2016. Disponível em:< https://cadernosdoceas.ucsal.br/index.php/cadernosdoceas/article/view/280/216>.

CASTRO-GÓMEZ, Santiago. La poscolonialidad explicada a lós niños. Popayán: Universidad del Cauca; Instituto Pensar, Universidad Javeriana, 2005.

; MENDIETA, Eduardo. "Introducción:la translocalización discursiva de Latinoamérica en tiempos de la globalización". In:__(coords.). Teorías sin disciplina: latinoamericanismo, poscolonialidad yglobalización en debate, 1998. México: Miguel Ángel Porrúa. Disponível em: <http://red.pucp.edu.pe/ridei/files/2011/08/214.pdf > . Acesso em: $11 \mathrm{dez}$. 2018.

CÈSAIRE, Aimé. Discurso sobre o colonialismo. Blumenau: Letras Contemporâneas, 2010 [1950]. 
COLLINS, Patricia Hill. Black feminist thought: knowledge, consciousness and politics of empowermente. 2. ed. New York: Routledge, 2000.

DAVIS, Angela. Mulheres, raça e classe. São Paulo: Boitempo, 2016.

DE CASTRO, Lola Aniyar. Criminologia da libertação. Trad. Sylvia Moretzsohn. Rio de Janeiro: ICC/Revan, 2005.

DEL OLMO, Rosa. A América Latina e sua criminologia. Rio de Janeiro: ICC/Revan, 2004.

DUARTE, Evandro Charles Piza. Criminologia \& racismo: introdução à criminologia brasileira. 1 ed. Curitiba: Juruá, 2011.

; QUEIROZ, Marcos V. Lustosa; COSTA, Pedro H. Argolo. A Hipótese Colonial, um diálogo com Michel Foucault: a Modernidade e o Atlântico Negro no centro do debate sobre Racismo e Sistema Penal. Universitas Jus, Brasília, v. 27, p. 01-31, 2015.

ESPINOSA-MIÑOSO Yuderkys. Una crítica descolonial a la epistemología feminista crítica. El Cotidiano, n. 184, p. 7-12, 2014. Disponível em: $<$ http://www.redalyc.org/pdf/325/32530724004.pdf >. Acesso em: 10 jan. 2019.

. Y la una no se mueve sin la otra: descolonialidad, antirracismo y feminismo. una trieja inseparablepara los procesos de cambio. Revista venezolana de estudios de la mujer, v. 21 , n. 46, p. 47-64, 2016.

FANON, Frantz. Os condenados da terra. Juiz de Fora: Editora UFJF, 2010 [1961].

FIGUEROA, Aurora Vergara; HURTADO, Katherine Arboleda. Feminismo afrodiaspórico: uma agenda emergente del feminismo negro em Colombia. Universitas humanística, v. 78, n. 78, p. 110-134, 2014.

FOX KELLER, Evelyn. Qual foi o impacto do feminismo na ciência? In: LOPES, Maria Margareth (Org.). Cadernos Pagu: Ciência, Substantivo Feminino Plural. Campinas, SP: Núcleo de Estudos de Gênero, Universidade Estadual de Campinas, n. 27, 2006. p. 13-34.

FLAUZINA, Ana Luiza Pinheiro. Corpo negro caído no chão: o sistema penal e o projeto genocida do Estado brasileiro. 2. ed. Brasília: Brado Negro, 2017.

. O feminicídio e os embates das trincheiras feministas. Discursos Sediciosos, Rio de Janeiro, n. 23/24, p. 95-104, 2016.

FRANKLIN, Naila Ingrid Chaves. O controle social e as mulheres negras: possibilidades e releituras para a criminologia feminista. Revista Brasileira de Ciências Criminais, São Paulo, Ed. RT, v. 135, ano 25, p. 487-518, set. 2017.

FREITAS, Felipe da Silva. Novas perguntas para criminologia brasileira: Poder, Racismo e Direito no centro da roda. Cadernos do CEAS, Salvador, n. 238, p. 489-499, 2016.

GÓES, Luciano. A tradução de Lombroso na obra de Nina Rodrigues: o racismo como base estruturante da criminologia brasileira. Rio de Janeiro: Revan, 2016. 
. Pátria exterminadora: o projeto genocida brasileiro. Revista Transgressões: ciências criminais em debate, Rio Grande do Norte, v. 5, n. 2, p. 53-79, 2017.

GOMES, Camilla de Magalhães. Gênero como categoria de análise decolonial. Civitas, Porto Alegre, v. 18, n. 1, p. 65-82, 2018.

GROSFOGUEL, Ramón. The epistemic decolonial turn: beyond political-economy paradigms. Cultural Studies, v. 21, p. 211-223, 2007.

HARAWAY, Donna. Saberes Localizados: a questão da ciência para o feminismo e o privilégio da perspectiva parcial. Cadernos Pagu, Campinas, n. 5, p. 04-41, 1995.

HOOKS, bell. Intelectuais negras. Porto Alegre: Revista Estudos Feministas, Porto Alegre, v. 3, n. 2, p. 464-478, 1995.

LÖWY, Ilana. Universalidade da ciência e conhecimentos situados. Cadernos Pagu, Campinas, n. 15 , p.15-38, 2000.

MEMMI, Albert. Retrato do colonizado precedido de retrato do colonizador. Rio de Janeiro: Paz e Terra, 1977 [1947].

MENDES, Soraia da Rosa. Criminologia feminista: novos paradigmas. São Paulo: Saraiva, 2014.

MIGLIEVICH-RIBEIRO, Adelia. Por uma razão decolonial: Desafios ético-políticoepistemológicos à cosmovisão moderna. Civitas - Revista de Ciências Sociais, [S.1.], v. 14, n. 1, p. 66-80, 2014. Disponível em: $<$ http://revistaseletronicas.pucrs.br/ojs/index.php/civitas/article/view/16181/10959>. Acesso em: 10 jan. 2019.

PIRES, Thula Rafaela de Oliveira. Criminologia Crítica e pacto narcísico: por uma crítica criminológica apreensível em pretuguês. Revista Brasileira de Ciências Criminais, São Paulo, Ed. RT, v. 135, ano 25, p. 541-562, 2017.

PRANDO, Camila Cardoso de Mello. A contribuição do discurso criminológico latino-americano para a compreensão do controle punitivo moderno: controle penal na América Latina. Veredas do Direito, Belo Horizonte, v. 3, p. 77-94, 2006.

QUIJANO, Aníbal. Colonialidad del poder y clasificacion social. Journal of World-Systems Research, v. 6, n. 2, p. 342-386, 2000. Disponível em: $<$ http://jwsr.pitt.edu/ojs/index.php/jwsr/article/view/228/240>.

RESTREPO, Eduardo; ROJAS, Axel. Inflexión decolonial: fuentes, conceptos y cuestionamientos. Popatán: Universidad del Cauca; Instituto Pensar, Universidad Javeriana, 2010.

SAID, Edward. Orientalismo: o Oriente como invenção do Ocidente. São Paulo: Cia das Letras, 2007 [1978].

SANTOS, Boaventura de Sousa; MENESES, Maria Paula (Orgs.). Epistemologias do Sul. SãoPaulo: Editora Cortez, 2010. 
SEGATO, Rita Laura. Gênero e colonialidade: em busca de chaves de leitura e de um vocabulário estratégico descolonial. e-cadernos ces (on-line), n. 18, 2012. Disponível em: $<$ http://journals.openedition.org/eces/1533>. Acesso em: 11 jan. 2019.

SCHIEBINGER, Londa. O feminismo mudou a ciência?. Bauru: EDUSC, 2001.

STRATHERN, Marilyn. O gênero da dádiva: problemas com as mulheres e problemas com a sociedade na Melanésia. Campinas: Editora da Unicamp, 2006.

WALSH, Catherine. Interculturalidad, Estado, Sociedad: Luchas (de)coloniales de nuestra época. Universidad Andina Simón Bolivar, Ediciones Abya-Yala: Quito, 2009.

ZAFFARONI, Eugenio Raúl. Em busca das penas perdidas: a perda da legitimidade do sistema penal. Trad. Vânia Romano Pedrosa. Rio de Janeiro: Revan, 1991.

. La mujer y el poder punitivo. In: Vigiladas y castigadas. Lima: CLADEM, 1992.

Trabalho enviado em 19 de fevereiro de 2019

Aceito em 19 de maio de 2020 